

\title{
Hf-based high-k dielectrics for p-Ge MOS gate stacks
}

Sivan Fadida, Felix Palumbo, Laura Nyns, Dennis Lin, Sven Van Elshocht, Matty Caymax, and Moshe Eizenberg

Citation: Journal of Vacuum Science \& Technology B 32, 03D105 (2014); doi: 10.1116/1.4837295

View online: http://dx.doi.org/10.1116/1.4837295

View Table of Contents: http://scitation.aip.org/content/avs/journal/jvstb/32/3?ver=pdfcov

Published by the AVS: Science \& Technology of Materials, Interfaces, and Processing

\section{Instruments for advanced science}
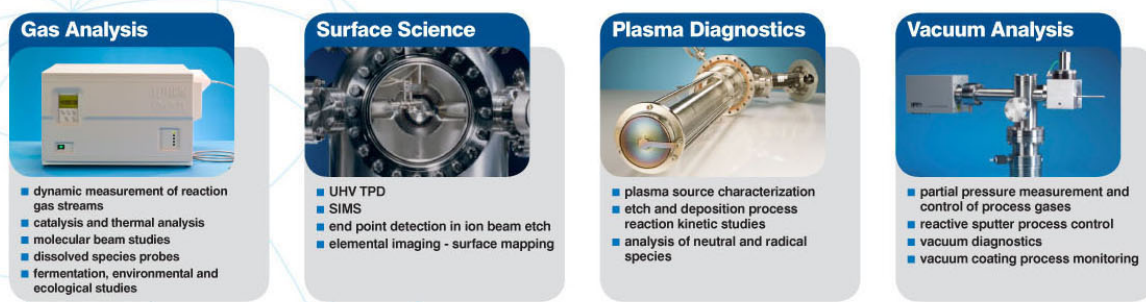

contact Hiden Analytical for further details

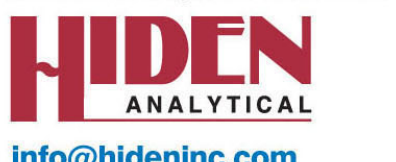

info@hideninc.com www.HidenAnalytical.com CLICK to view our product catalogue 


\title{
Hf-based high-k dielectrics for p-Ge MOS gate stacks
}

\author{
Sivan Fadida ${ }^{\text {a) }}$ and Felix Palumbo \\ Department of Materials Science and Engineering, Technion-Israel Institute of Technology, \\ Haifa 3200003, Israel \\ Laura Nyns, Dennis Lin, Sven Van Elshocht, and Matty Caymax \\ Imec, Kapeldreef 75, B-3001 Leuven, Belgium \\ Moshe Eizenberg \\ Department of Materials Science and Engineering, Technion-Israel Institute of Technology, \\ Haifa 3200003, Israel
}

(Received 17 September 2013; accepted 18 November 2013; published 3 December 2013)

\begin{abstract}
The physical and electrical properties of the gate stack high-k/ $\mathrm{Al}_{2} \mathrm{O}_{3} / \mathrm{GeO}_{2} / \mathrm{p}-\mathrm{Ge}$ were studied in detail, where the high-k is either $\mathrm{HfO}_{2}$ or alloyed $\mathrm{HfO}_{2}\left(\mathrm{HfZrO}_{\mathrm{y}}, \mathrm{HfGdO}_{\mathrm{x}}\right.$, or $\left.\mathrm{HfAlO}_{\mathrm{x}}\right)$. Electrical measurements combined with $\mathrm{x}$-ray photoelectron spectroscopy chemical bonding analysis and band alignment determination were conducted in order to assess the suitability of hafnium-based high-k for this kind of gate stacks, with emphasis on low density of interface states and border traps. $\mathrm{HfAlO}_{\mathrm{x}}$ was found to be the most promising high-k from those studied. The authors have also found that the current- voltage trends for the various systems studied can be explained by the band alignment of the samples obtained by our x-ray photoelectron spectroscopy analysis. (C) 2014 American Vacuum Society. [http://dx.doi.org/10.1116/1.4837295]
\end{abstract}

\section{INTRODUCTION}

Germanium is a leading candidate to serve as a future channel material of transistors due to its high carrier mobility (especially holes) with respect to $\mathrm{Si}^{1}{ }^{1}$ Replacing $\mathrm{Si}$ channels with Ge leads to new challenges, stemming from lower interface quality and formation of unstable oxides. These properties of Ge require an effective passivation layer in order to achieve proper stability and electrical properties of the interface. Many attempts were done to optimize the passivation of the interface using several materials. ${ }^{2-5}$ Passivation layers and carriers trapping at the Ge/oxide interface have become the core topic of $\mathrm{Ge}$ related researches.

$\mathrm{GeO}_{2}$ used to be considered the cause for the low interface quality, and many attempts were made in order to avoid Ge oxidation. This was found to be very complicated. Moreover, very good passivation was achieved by growing a thin $\mathrm{GeO}_{\mathrm{x}}(\mathrm{x}<2)$ layer as part of the passivation. ${ }^{6,7}$ Since several routes for passivation of $\mathrm{Ge}$ were found, the current challenge in Ge MOS research is to find a gate dielectric with the desired properties. This dielectric should have a large band gap, large band offsets with respect to Ge, chemical and thermal stability on top of Ge or on top of the chosen passivation layer, and a high dielectric constant (high-k). Being at the center of attention as a high-k dielectric for $\mathrm{Si}$ MOSFET, $\mathrm{HfO}_{2}$ is a natural candidate as a high-k dielectric for $\mathrm{Ge}$ gate stacks as well. Many attempts were made to alloy $\mathrm{HfO}_{2}$ with another metal oxide in order to obtain a ternary oxide such as $\mathrm{Hf}_{\mathrm{x}} \mathrm{Al}_{1-\mathrm{x}} \mathrm{O}_{2}$ (Refs. 8 and 9) or $\mathrm{Hf}_{\mathrm{x}} \mathrm{Gd}_{1-\mathrm{x}} \mathrm{O}_{2}$ (Ref. 10) with the goal of further improving its properties. ${ }^{11}$ Some of the goals hoped to be achieved by alloying $\mathrm{HfO}_{2}$ are increase of the dielectric constant, increase of the band gap and band offsets with respect to Ge,

${ }^{\text {a)} E l e c t r o n i c ~ m a i l: ~ s i v a n f a @ t x . t e c h n i o n . a c . i l ~}$ reduction of oxygen vacancies, increase of the crystallization temperature, reduction of bulk and interface states, etc. It should be noted that usually in high-k dielectrics an increase in the dielectric constant is accompanied by a decrease in the band gap, ${ }^{12}$ so not all goals can be achieved for a certain metal oxide. Unfortunately, $\mathrm{HfO}_{2}$ was found to be unstable on $\mathrm{GeO}_{2} \cdot{ }^{13,14}$ On the other hand, $\mathrm{Al}_{2} \mathrm{O}_{3}$ forms a very good interface with $\mathrm{GeO}_{2}$ (Ref. 15) but has a relatively low dielectric constant that hardly defines it as a high-k dielectric. Therefore, a multilayer gate stack of the structure: high- $\mathrm{k} / \mathrm{Al}_{2} \mathrm{O}_{3} / \mathrm{GeO}_{2} / \mathrm{Ge}$ where the high- $\mathrm{k}$ is $\mathrm{HfO}_{2}$ or alloyed $\mathrm{HfO}_{2}$ is considered in this study. This multilayer structure uses the best qualities of each layer- good interface qualities, high-k value, and adequate band alignment, as was shown to be effective in previous reports. ${ }^{16-18}$ However, with such complex structures, the electrical characterization of the MOS capacitor is not straightforward and is affected by each of the layers and interfaces. For instance, density of interface traps $\left(D_{i t}\right)$ analysis using the conductance method can be difficult to interpret in such multilayer stacks since the loss in conductance cannot be attributed only to interface traps but also to oxide traps and border traps. We combine several electrical methods with chemical bonding characterization in order to determine which Ge MOS stack has the most promising properties. In this study, we are not necessarily focused in trying to obtain a minimal effective oxide thickness but in thoroughly understanding the chemical and physical properties of such structures, and the dependence of the electrical properties on those.

\section{EXPERIMENT}

\section{A. Sample fabrication}

The experiments were performed on $300 \mathrm{~mm}$ p-type Geon-Si wafers where $1 \mu \mathrm{m}$ of undoped $\mathrm{Ge}$ was grown 
epitaxially on top of the Si substrate. Afterwards, the wafers were cleaned for $30 \mathrm{~s}$ in a diluted HF solution ( $2 \mathrm{wt} . \%)$ to remove most of the native oxide. After the HF dip, the Ge surface was reoxidized in a controlled manner to obtain $\mathrm{GeO}_{2}$ layers of $\sim 0.7 \mathrm{~nm}$, as measured by $\mathrm{x}$-ray photoelectron spectroscopy (XPS). Reoxidation was done during the atomic layer deposition (ALD) of $\sim 2 \mathrm{~nm} \mathrm{Al}_{2} \mathrm{O}_{3}$ by means of the tri-methyl-aluminum (TMA) $/ \mathrm{O}_{3}$ process. $\mathrm{GeO}_{\mathrm{x}}$ formation during this ALD process has been described before. ${ }^{19,20}$ On top of the $\mathrm{Al}_{2} \mathrm{O}_{3} / \mathrm{GeO}_{2}$ stack, $\sim 4 \mathrm{~nm}$ of an Hf-based high-k was deposited. These high-k layers consisted of $\mathrm{HfO}_{2}, \mathrm{HfAlO}_{\mathrm{x}}, \mathrm{HfGdO}_{\mathrm{x}}$, or $\mathrm{HfZrO}_{\mathrm{y}}$ and were all deposited by ALD. The Hf:M atomic ratio was 1:1. The ALD was performed at $300^{\circ} \mathrm{C}$ in a cross-flow ASM Pulsar 3000 reactor, attached to a Polygon8300 platform. The precursors used in the ALD process were: $\mathrm{HfCl}_{4}$ and $\mathrm{H}_{2} \mathrm{O}$ for $\mathrm{HfO}_{2}$ deposition, TMA and $\mathrm{Gd}(\mathrm{iPrCp})_{3}$ combined with $\mathrm{HfCl}_{4}$ and $\mathrm{H}_{2} \mathrm{O}$ for $\mathrm{HfAlO}_{\mathrm{x}}$ and $\mathrm{HfGdO}_{\mathrm{x}}$ deposition, respectively. Only $\mathrm{HfZrO}_{\mathrm{y}}$ was deposited at $250^{\circ} \mathrm{C}$ in a top-flow ALD reactor of Applied Materials using tetrakis diethyl amino-hafnium, tetrakis diethyl amino-zirconium, and $\mathrm{H}_{2} \mathrm{O}$. A reference sample with the structure $\sim 4 \mathrm{~nm} \mathrm{Al}_{2} \mathrm{O}_{3} / \mathrm{GeO}_{2}$ was also fabricated on $\mathrm{Ge}$. Pt was used as the gate electrode. All samples underwent a postdeposition anneal for $30 \mathrm{~min}$ at $400{ }^{\circ} \mathrm{C}$ in a gas-flow furnace using a forming gas $90 \% \mathrm{~N}_{2}+10 \% \mathrm{H}_{2}$ ambient. These annealing conditions were chosen after the results were compared with those of vacuum annealing $\left(10^{-7} \mathrm{Torr}, 30 \mathrm{~min}\right.$ in $400^{\circ} \mathrm{C}$ ) and found to be significantly better.

\section{B. Characterization}

XPS measurements were conducted in a Thermo VG Scientific Sigma Probe system using a monochromatic Al $\mathrm{Ka}(1486.6 \mathrm{eV}) \mathrm{x}$-ray source. Curve fitting was done by the XPSPEAK4.1 fitting program using a Gaussian-Lorentzian convolution $(15 \%)$ with a Shirley-type background. Different XPS measurements induce different charging levels of the insulator sample. Charging compensation in all samples was done by aligning the $\mathrm{Al} 2 \mathrm{p}$ peak. This charge removal method can be somewhat problematic when dealing with the $\mathrm{HfAlO}_{\mathrm{x}}$ sample, since $\mathrm{Al}$ can also be found in the $\mathrm{HfAlO}_{\mathrm{x}}$ layer. In order to assure the charge removal procedure, two additional etched samples were prepared for the $\mathrm{HfO}_{2}$ and $\mathrm{HfAlO}_{\mathrm{x}}$ samples. The top layer was gradually etched (1:10 HF and 1:20 HF, respectively) in order to enable the observation of the Ge $3 \mathrm{~d}$ peak from the substrate, along with the $\mathrm{Hf} 4 \mathrm{f}$ and $\mathrm{Al} 2 \mathrm{p}$ peaks. In this way, it was possible to remove the charging effect using the Ge $3 \mathrm{~d}$ $(29.4 \mathrm{eV})$ transition. The reference sample was used in order to determine the band edges of $\mathrm{Ge}$ and $\mathrm{Al}_{2} \mathrm{O}_{3}$. Cross sectional transmission electron microscopy (TEM) samples were prepared by conventional polishing and were examined in a $200 \mathrm{keV}$ FEI Tecnai G2 T20 Twin TEM.

All electrical measurements were performed at room temperature in a probe station sealed from light. Steady state capacitance voltage $(\mathrm{C}-\mathrm{V})$ measurements were conducted using an HP4284 LCR meter at various frequencies (10 $\mathrm{kHz}-1 \mathrm{MHz}$ ). Current voltage (I-V) measurements were conducted using an Agilent 4155C parameter analyzer under a negative bias in order to test the leakage current behavior in accumulation conditions.

\section{RESULTS AND DISCUSSION}

TEM micrographs presented in Fig. 1 show uniform layers. No crystallinity or phase separations in the high-k ternary or binary oxides are observed. Also, for none of the samples the thin $\mathrm{GeO}_{2}$ layer is observed. This is probably due to similar contrasts caused by similar molecular weights of $\mathrm{Al}_{2} \mathrm{O}_{3}$ and $\mathrm{GeO}_{2}$. In order to verify that indeed there is a layer of oxidized $\mathrm{Ge}$, we have examined the $\mathrm{Ge} 3 \mathrm{~d}$ peak of the etched samples. The spectrum is taken from a region where there is still a signal from the top high-k layer meaning the layer was not completely etched. This examination confirms that oxidized Ge is present in the samples (Fig. 2). Two oxidation states of $\mathrm{Ge}$ are identified: $\mathrm{Ge}^{4+}$ and $\mathrm{Ge}^{2+}$, where the compounds ratio calculated from the peaks areas is $20: 3$. From this ratio, we can surely state that the type of the oxide is mostly $\mathrm{GeO}_{2}$ since the dominant oxidized $\mathrm{Ge}$ peak corresponds to the oxidation state of $\mathrm{Ge}^{4+}$. $\mathrm{Al}$ bonding to oxidized Ge at the $\mathrm{Al}_{2} \mathrm{O}_{3} / \mathrm{GeO}_{2}$ interface can also contribute to the oxidized $\mathrm{Ge}$ peak, but probably in a smaller amount.

$\mathrm{C}-\mathrm{V}$ Measurements of various frequencies were conducted on the samples. It is clearly seen from the C-V measurements (Fig. 3) that each of the elements added to $\mathrm{HfO}_{2}$ improves the $\mathrm{C}-\mathrm{V}$ characteristics as will be discussed below. This observation is consistent for all frequencies measured. $\mathrm{C}-\mathrm{V}$ curves at low frequencies [Fig. 3(a)] show, as expected, the weak inversion hump behavior. When comparing the weak inversion hump area for all samples [inset of Fig. 3(a)], we see a clear difference between the samples. Since

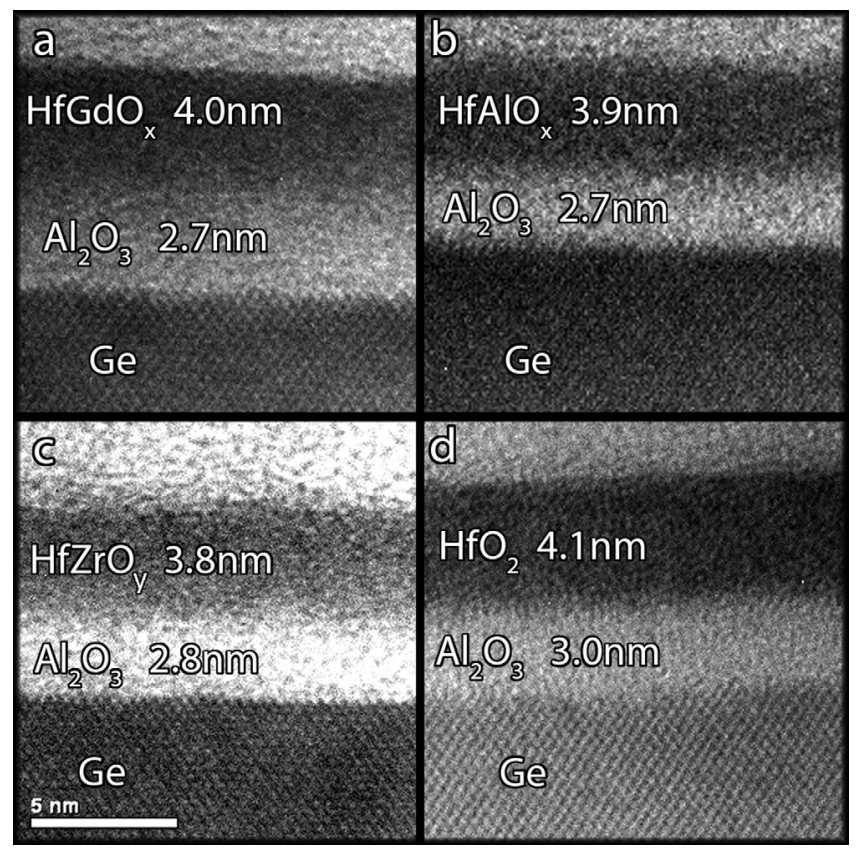

FIG. 1. Cross section TEM micrographs of (a) HfGdOx, (b) HfAlOx, (c) $\mathrm{HfZrOy}$, and (d) $\mathrm{HfO}_{2}$. All images show uniform high-k layers with quite abrupt interfaces. 


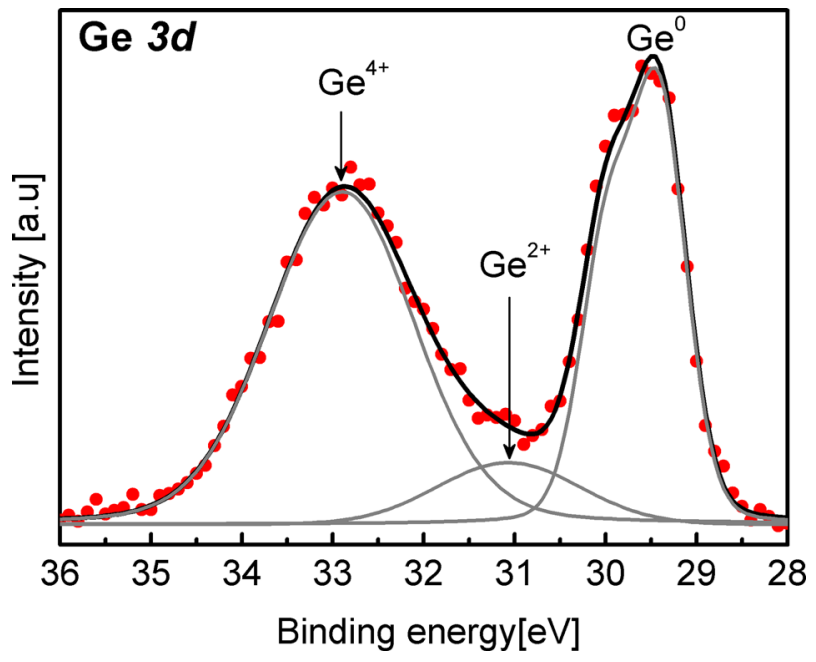

FIG. 2. (Color online) Ge $3 \mathrm{~d}$ spectra (background subtracted) taken from the $\mathrm{HfAlO}_{\mathrm{x}}$ sample after a graded etch procedure. The spectrum is taken from a region where there is still a signal from the top high-k layer meaning the layer was not completely etched. This spectrum shows the major oxidized $\mathrm{Ge}$ component is $\mathrm{Ge}^{4+}$ corresponding to $\mathrm{GeO}_{2}$.

this hump area is proportional to the amount of mid-gap states, ${ }^{21}$ we conclude that the reduction of these states is significant in all $\mathrm{HfMO}_{\mathrm{x}}$ samples when compared to the $\mathrm{HfO}_{2}$ sample. The smallest weak inversion hump area is of the $\mathrm{HfZrO}_{\mathrm{y}}$ sample.


FIG. 3. (Color online) $\mathrm{C}-\mathrm{V}$ curves of all samples at (a) $10 \mathrm{kHz}$ and at (b) $100 \mathrm{kHz}$. Inset of Fig. 3(a) shows a magnification of the weak inversion region showing a clear difference between samples, although all have the same passivation structure. Figure 3(b) shows the difference of the relative permittivity value.
Figure 3(b) demonstrates the differences between the Hfbased high-k dielectrics in terms of the dielectric constant. Using the accumulation capacitance values and the total thickness of the dielectric stack measured by TEM, we have calculated the effective dielectric constant of the $\mathrm{HfMO}_{\mathrm{x}} / \mathrm{Al}_{2} \mathrm{O}_{3} / \mathrm{GeO}_{2}$ dielectric stack for our samples. The effective dielectric constant was found to be 8.5, 7.7, 9.5, and 9.5 for $\mathrm{M}$ being $\mathrm{Hf}, \mathrm{Al}, \mathrm{Gd}$, and $\mathrm{Zr}$, respectively. Those values are lower than what we would have expected for $\mathrm{Al}_{2} \mathrm{O}_{3} / \mathrm{HfMO}_{\mathrm{x}}$ bilayers. The lowering of the effective $\mathrm{k}$ is probably due to the $\mathrm{GeO}_{2}$ layer. We can conclude that adding $\mathrm{Zr}$ or $\mathrm{Gd}$ to $\mathrm{HfO}_{2}$ increases the effective permittivity, while $\mathrm{Al}$ addition decreases it. This conclusion is drawn since the difference between the samples is in the top layer only.

The $\mathrm{D}_{\text {it }}$ analysis (Fig. 4), preformed by the conductance method, ${ }^{22}$ indicates a large trap density around midgap repeatedly for all samples. When the hump area is compared to the $\mathrm{D}_{\text {it }}$ value, a good correlation is observed for $\mathrm{HfO}_{2}$, $\mathrm{HfAlO}_{\mathrm{x}}$, and $\mathrm{HfZrO}_{\mathrm{y}}$ but not for the $\mathrm{HfGdO}_{\mathrm{x}}$ sample. The traditional conductance method uses the assumption that the loss in the measured conductance is only caused by $\mathrm{D}_{\mathrm{it}}$. This assumption is reasonable for $\mathrm{SiO}_{2} / \mathrm{Si}$ stacks, but may not be valid for the complex multi-layer stacks studied here, or for the majority of alternative channel materials for MOS capacitors. $^{22}$ Therefore, for instance, the C-V of the $\mathrm{HfGdO}_{\mathrm{x}}$ sample does not show such a good correlation with the $D_{i t}$ analysis.

In order to understand the root cause of this inconsistency, we used the quasistatic $\mathrm{C}-\mathrm{V}$ method $^{23}$ for a qualitative evaluation of interface traps as well as border traps (Fig. 5). This method enables to separate between the contributions of each kind of traps, a separation which is not possible in the conductance method. Border traps cause broadening of the quasistatic $\mathrm{C}-\mathrm{V}$ curve, while interface traps increase its minimum capacitance. ${ }^{20}$ The minimum capacitance of the $\mathrm{HfGdO}_{\mathrm{x}}$ sample curve implies a relatively low $\mathrm{D}_{\text {it }}$, which fits the low hump area shown in Fig. 3(a). On the other hand, the relative high width of the $\mathrm{HfGdO}_{\mathrm{x}}$ quasistatic $\mathrm{C}-\mathrm{V}$ curve implies a high border traps concentration, which can explain



FIG. 4. (Color online) $\mathrm{D}_{\text {it }}$ calculated for all samples using the conductance method. Here again a clear difference in the $\mathrm{D}_{\mathrm{it}}$ characterization is observed when the $\mathrm{HfGdO}_{\mathrm{x}}$ sample stands out with the highest $\mathrm{D}_{\mathrm{it}}$ among all samples studied. 


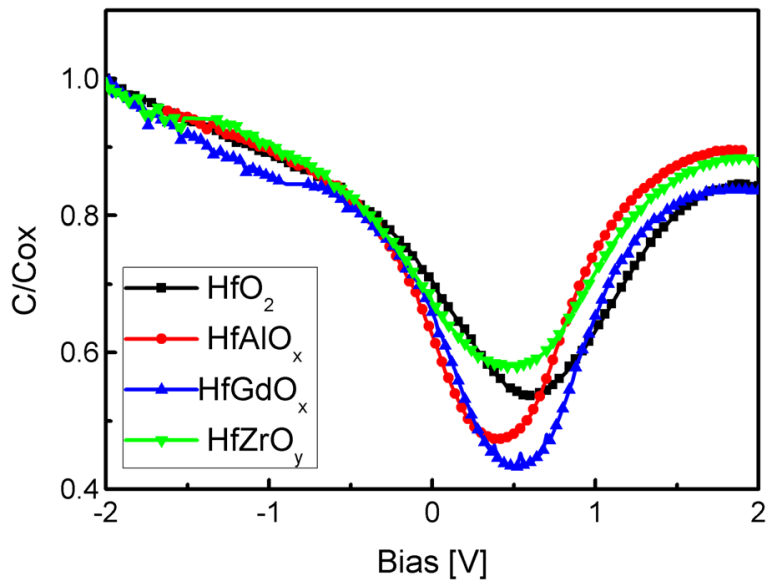

FIG. 5. (Color online) Quasistatic C-V curves of all samples. Here the $\mathrm{HfZrO}_{\mathrm{y}}$ sample shows the highest $\mathrm{D}_{\mathrm{it}}$ (shallowest curve) and the $\mathrm{HfGdO}_{\mathrm{x}}$ sample (together with the $\mathrm{HfO}_{2}$ sample) shows the highest density of border traps (widest curve).

the high conductance loss measured for this sample. Therefore, we conclude that this conductance loss is due to border traps rather than interface traps. Here it is again clear that the $\mathrm{HfO}_{2}$ sample has the worst properties in terms of trap densities in comparison to the studied ternary $\mathrm{HfMO}_{\mathrm{x}}$ samples $(\mathrm{M}=\mathrm{Al}, \mathrm{Gd}, \mathrm{Zr})$. Based on the quasistatic $\mathrm{C}-\mathrm{V}$ and the $D_{i t}$ analysis, it appears that the $\mathrm{HfAlO}_{\mathrm{x}}$ sample has the best properties when considering interface and border traps.

This conclusion is further validated when we analyze the oxygen bonding by XPS (Fig. 6). The O1s spectra collected from the samples are relatively similar. High similarity is observed for the O1s spectra of $\mathrm{HfO}_{2}$ and $\mathrm{HfZrO}_{\mathrm{y}}$ due to a significant chemical similarity between $\mathrm{Zr}$ and $\mathrm{Hf}$. Each of the four spectra presented in Fig. 6(a) consists of one major peak at a binding energy of $\sim 530 \mathrm{eV}$ corresponding to the Hf-O bonding. The same binding energy and full width at half maximum are observed in the Hf-O peak of all the samples. This implies that the Hf-O bonding does not change drastically when another metal atom is added to $\mathrm{HfO}_{2}$. The second component of the $\mathrm{O} 1 \mathrm{~s}$ spectrum is at a binding energy of $\sim 531 \mathrm{eV}$ corresponding to the Al-O bonding from the underlying $\mathrm{Al}_{2} \mathrm{O}_{3}$. The intensity of this peak is relatively smaller than the Hf-O peak, but is larger for the $\mathrm{HfAlO}_{\mathrm{x}}$ sample since the Al-O bonding exists in the top high-k layer in addition to its contribution from the underlying $\mathrm{Al}_{2} \mathrm{O}_{3}$. Another small component that exists for all samples is at a binding energy of $\sim 532.5 \mathrm{eV}$ corresponding to $\mathrm{C}-\mathrm{O}$ bonding from surface contamination. In the O1s spectrum of the $\mathrm{HfGdO}_{\mathrm{x}}$ sample, we can clearly see another component that is not observed in the other samples. The detailed peak fitting of the O1s spectrum for this sample is presented in Fig. 6(b). The additional component at binding energy of $\sim 531.7 \mathrm{eV}$ is attributed to O-H bonding due to water adsorption. Gd oxide, as well as other rare earth oxides, is known for its hygroscopic nature. ${ }^{24} \mathrm{We}$ assume that this leads to the observed high defect density and also border traps.

Another indication for the high-k stack quality is the $\mathrm{C}-\mathrm{V}$ hysteresis measurement (Fig. 7). The measurement was done

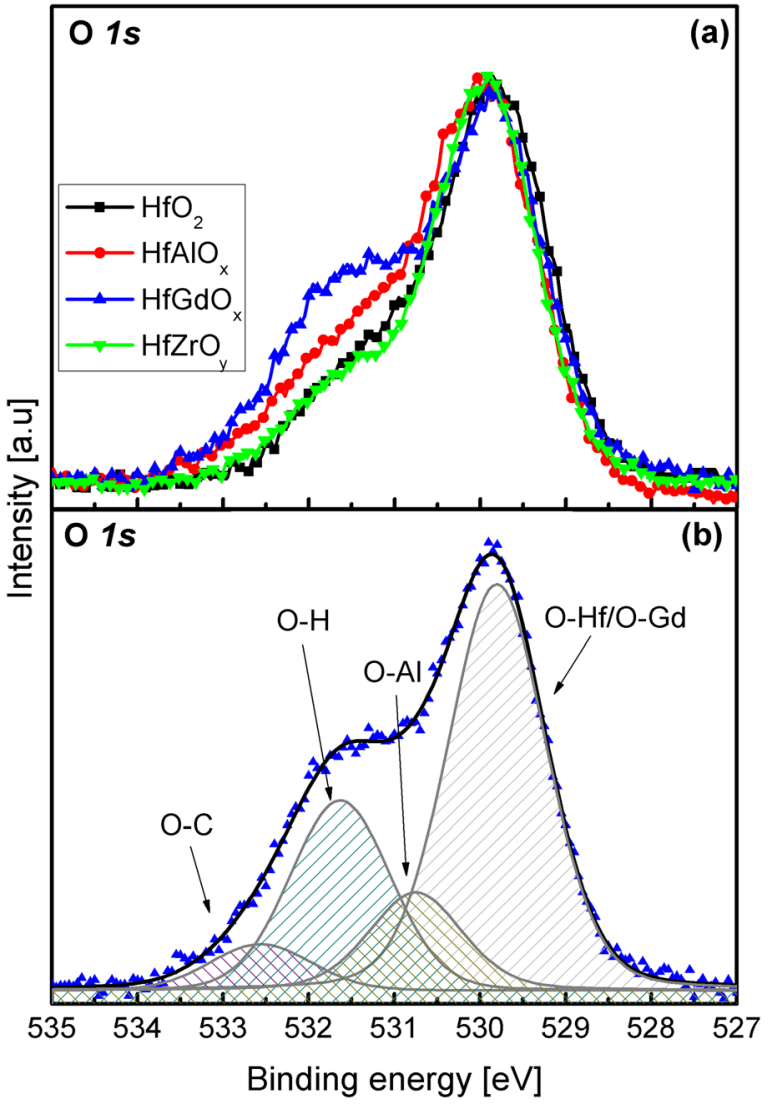

FIG. 6. (Color online) (a) O1s spectra (background subtracted) taken from all samples. The figure shows the data points as collected without peak fitting. (b) O1s spectrum (background subtracted) taken from the $\mathrm{HfGdO}_{\mathrm{x}}$ sample. Peak fitting reveals four different types of oxygen bonding (marked), including $\mathrm{O}-\mathrm{H}$ bonding attributed to water adsorption.

in a retrace mode where the voltage was swept from inversion to accumulation and back to inversion. Here, in contrast to the other electrical characterizations done, there is no big difference between the $\mathrm{HfO}_{2}$ and the $\mathrm{HfGdO}_{\mathrm{x}}$ and $\mathrm{HfZrO}_{\mathrm{y}}$ samples, and all show a large hysteresis $(0.6 \mathrm{~V}, 0.7 \mathrm{~V}$, and $0.6 \mathrm{~V}$, respectively), indicating a large density of charged

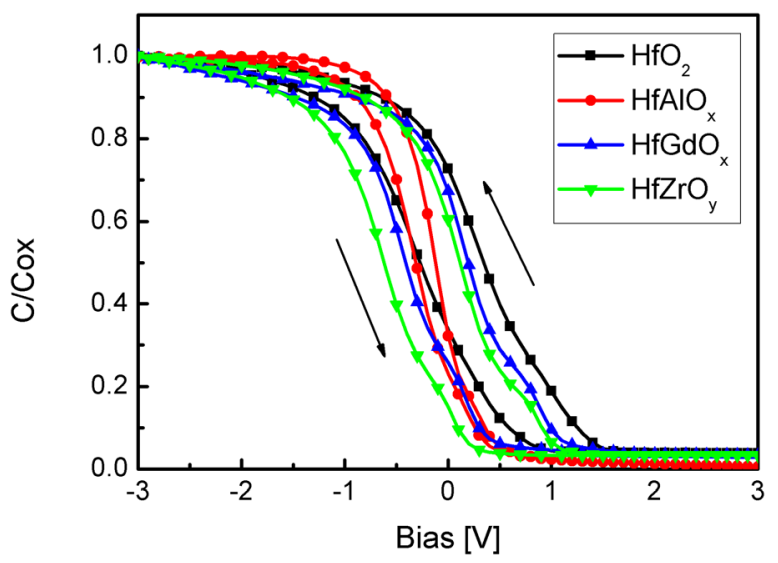

FIG. 7. (Color online) Hysteresis C-V curves at $100 \mathrm{kHz}$. The width of the hysteresis loop is $0.6-0.7 \mathrm{~V}$ for the $\mathrm{HfO}_{2} \mathrm{HfZrO}_{\mathrm{x}}$ and $\mathrm{HfGdO}_{\mathrm{x}}$ samples, while it is only $0.2 \mathrm{~V}$ for the $\mathrm{HfAlO}_{\mathrm{x}}$ sample. 
defects, namely border traps. ${ }^{25,26}$ The border traps density $\left(\mathrm{N}_{\mathrm{bt}}\right)$ was estimated using

$$
N_{\mathrm{bt}}=\frac{\Delta V \cdot C_{\mathrm{ox}}}{q},
$$

where $\Delta V$ is the hysteresis in $\mathrm{V}, C_{\mathrm{ox}}$ is the oxide capacitance in $\mathrm{F} / \mathrm{cm}^{2}$, and $q$ is the elementary charge in C. The $N_{\mathrm{bt}}$ values are $4.2 \cdot 10^{12}, 4.7 \cdot 10^{12}, 5.5 \cdot 10^{12}\left(\mathrm{~cm}^{-2}\right)$ for $\mathrm{HfO}_{2}, \mathrm{HfGdO}_{\mathrm{x}}$, and $\mathrm{HfZrO}_{\mathrm{y}}$, respectively.

On the other hand, it is clear that the $\mathrm{HfAlO}_{\mathrm{x}}$ sample is with the smallest hysteresis measured $(0.2 \mathrm{~V})$ and $N_{\mathrm{bt}}$ of $7.25 \times 10^{11}\left(\mathrm{~cm}^{-2}\right)$. This corresponds well with the previous results and is another validation of the relatively low concentration of border traps in the $\mathrm{HfAlO}_{\mathrm{x}}$ sample.

Current-voltage (I-V) measurements were also conducted. The curves (Fig. 8) are presented as a function of the electric field, $E(\mathrm{~V} / \mathrm{cm})$. The results show a significant difference between $\mathrm{HfAlO}_{\mathrm{x}}$ and the other high-k studied. While $\mathrm{HfO}_{2}, \mathrm{HfGdO}_{\mathrm{x}}$, and $\mathrm{HfZrO}_{\mathrm{y}}$ display similar I-V curves, with the same trend and the same level of leakage current, the leakage current of the $\mathrm{HfAlO}_{\mathrm{x}}$ containing sample is one order of magnitude lower in the high field regime. In the low field regime, the leakage current of the $\mathrm{HfAlO}_{\mathrm{x}}$ sample seems slightly higher than for the other samples. Since it is very close to the sensitivity limit of the equipment, we believe it can be considered as noise fluctuation.

In order to understand the root cause of this phenomenon, the band alignments of the samples were determined using XPS further to our previous work on the Hf- $\mathrm{Zr}$ oxide system. ${ }^{27}$ In this method, ${ }^{28,29}$ the valence band offset (VBO) from the band edge of the substrate is measured by the XPS low energy spectrum, and the band gap is measured using the O1s energy loss spectrum. Then, the conduction band offset $(\mathrm{CBO})$ is calculated by

$$
\mathrm{CBO}=E g_{\text {oxide }}-E g_{\mathrm{Ge}}-\mathrm{VBO},
$$

where $E g_{\text {oxide }}$ and $E g_{\text {Ge }}$ are the oxide and $G e$ band gaps, respectively. We have used a reference sample $\left(\mathrm{Al}_{2} \mathrm{O}_{3} / \mathrm{GeO}_{2} / \mathrm{Ge}\right)$ for the determination of the $\mathrm{Al}_{2} \mathrm{O}_{3}$ band



FIG. 8. (Color online) J-E curves for all samples showing a significant difference in the leakage current of HfAlOx sample under high electric fields.

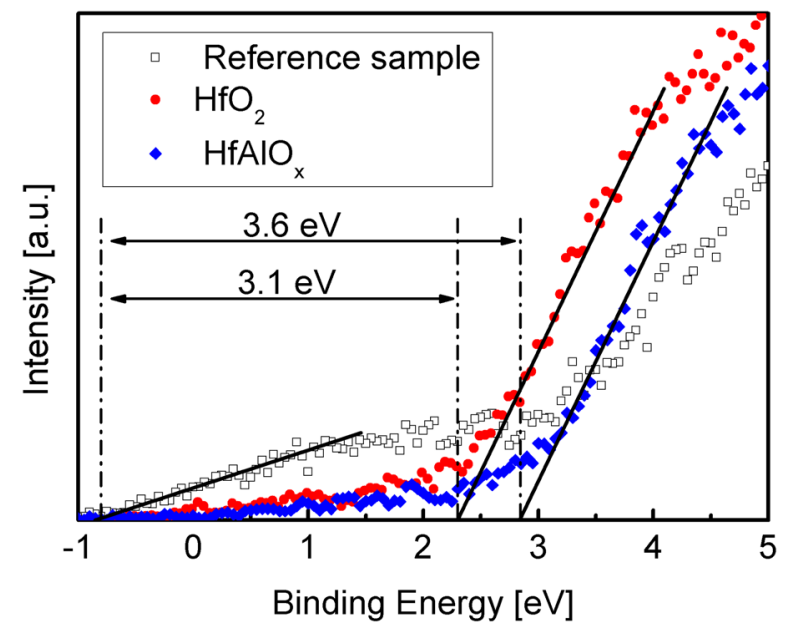

FIG. 9. (Color online) Valence band spectra for the $\mathrm{HfO}_{2} \mathrm{HfAlO}_{\mathrm{x}}$ and the reference sample. The first onset for the reference sample spectrum (empty squares) represents electrons ejected from the Ge valence band. The onset marked on the $\mathrm{HfO}_{2}$ spectrum represents the electrons ejected from the $\mathrm{HfO}_{2}$ valence band. The difference between them is the $\mathrm{VBO}$ of $\mathrm{HfO}_{2}$ relative to Ge. The same holds for the $\mathrm{HfAlO}_{\mathrm{x}}$ spectrum.

gap and $\mathrm{VBO}$ with respect to $\mathrm{Ge}$. The band gaps of $\mathrm{Al}_{2} \mathrm{O}_{3}$ $(6.9 \mathrm{eV})$ and $\mathrm{HfO}_{2}(5.4 \mathrm{eV})$ fit previous reports of amorphous ALD thin layers. ${ }^{30,31}$ The VBO of the Hf based samples was measured with respect to the reference sample (Fig. 9). The band alignment is presented in Fig. 10. Here, again, the $\mathrm{HfAlO}_{\mathrm{x}}$ sample stands out: only in this high-k dielectric the $\mathrm{VBO}$ with respect to $\mathrm{Ge}$ is larger than the $\mathrm{VBO}$ of $\mathrm{Al}_{2} \mathrm{O}_{3}$ (3.6 and $3.1 \mathrm{eV}$, respectively), while for the other dielectrics, it is equal to the $\mathrm{VBO}$ of $\mathrm{Al}_{2} \mathrm{O}_{3}$ or smaller $(3.0-3.1 \mathrm{eV})$. Examination of the $\mathrm{CBO}$ shows no difference between the samples. The CBO of the Hf-based high-k dielectrics with respect to $\mathrm{Ge}$ are in the range of $1.5-1.7 \mathrm{eV}$, all significantly smaller than the $\mathrm{CBO}$ of $\mathrm{Al}_{2} \mathrm{O}_{3}$ with respect to $\mathrm{Ge}(3.1 \mathrm{eV})$.

The band alignment shows that the $\mathrm{HfAlO}_{\mathrm{x}}$ sample has a significantly larger and thicker barrier for hole tunneling from the valence band as illustrated in Fig. 11. It also shows that the barrier for electron tunneling from the conduction band is the same for all samples and is dominated by the $\mathrm{Al}_{2} \mathrm{O}_{3}$ large $\mathrm{CBO}$. From these observations, we suggest that the reduction in the leakage current of the HfAlOx sample (Fig. 8) can be explained by the reduction of hole tunneling current through the high-k dielectric. The dominant

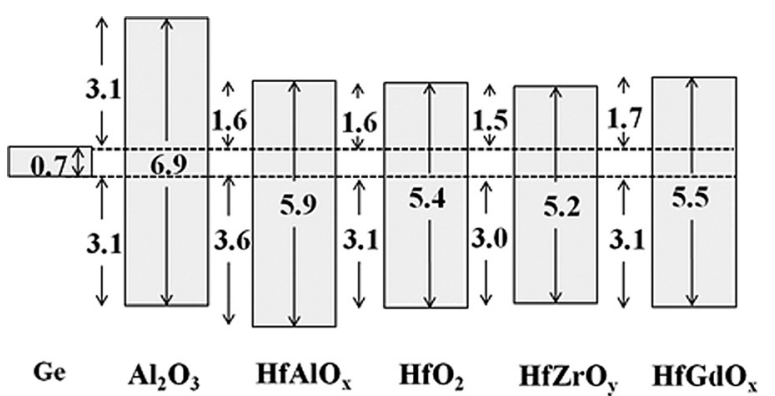

FIG. 10. Band alignment for all samples studied was determined using XPS. All values marked are given in eV. $\mathrm{HfAlO}_{\mathrm{x}}$ shows the largest $\mathrm{VBO}$ with respect to Ge while no significant difference is observed in the $\mathrm{CBO}$. 


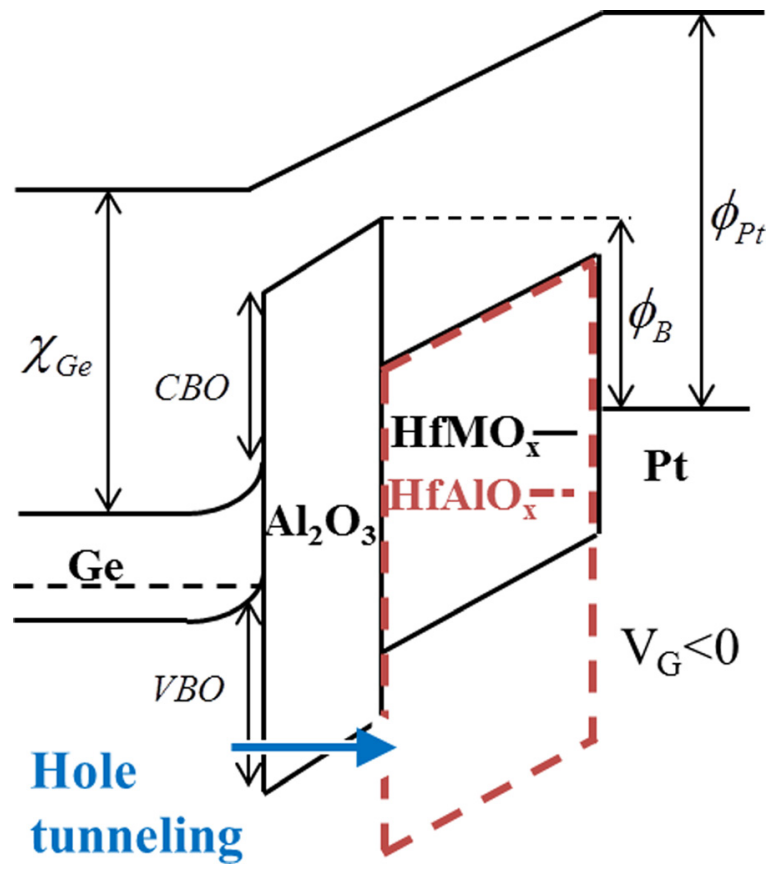

FIG. 11. (Color online) Schematic band diagram for the p-Ge MOS structures studied. The dashed red line represents the HfAlOx sample which has a larger $\mathrm{VBO}$ than the one of $\mathrm{Al}_{2} \mathrm{O}_{3}$. The hole tunneling is illustrated with the blue arrow.

mechanism of transport in the studied stacks cannot be determined without conducting further experiments. Beside the energy barrier for tunneling, we must consider that the effective mass of the holes in $\mathrm{HfO}_{2}$ can change when another element is added to $\mathrm{HfO}_{2}$. However, a change in the energy barrier has a larger impact on the tunneling current than a change in the effective mass. ${ }^{32}$

In order to establish this conclusion, we have also measured the leakage current of the reference sample with the structure $\mathrm{Al}_{2} \mathrm{O}_{3} / \mathrm{GeO}_{2} / \mathrm{Ge}$. The results are shown in Fig. 12 along with the $\mathrm{J}-\mathrm{V}$ curves of the $\mathrm{HfO}_{2}$ sample and of the $\mathrm{HfAlO}_{\mathrm{x}}$ sample for comparison. The leakage current of the reference sample is indeed higher than that of the $\mathrm{HfAlO}_{\mathrm{x}}$ sample, as can be expected based on the different VBO of $\mathrm{Al}_{2} \mathrm{O}_{3}$ and $\mathrm{HfAlO}_{\mathrm{x}}$. However, the leakage is still lower than

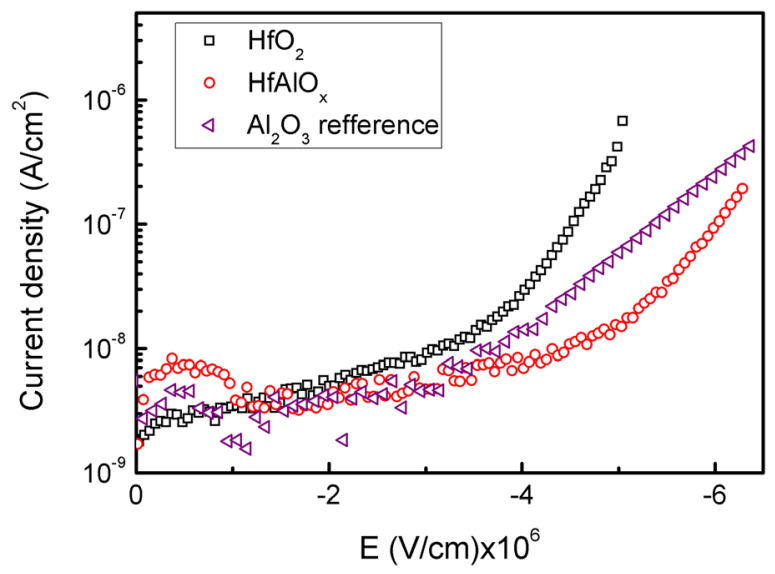

FIG. 12. (Color online) J-E curves for $\mathrm{HfO}_{2}, \mathrm{HfAlO}_{\mathrm{x}}$, and the reference sample. that of the $\mathrm{HfO}_{2}$ sample. One possible explanation to the reduced leakage current in the reference sample is relying on the assumption that more than one tunneling mechanism is active and as an example the tunneling of electrons in the opposite direction to that of holes cannot be neglected. The barrier for electron tunneling $\phi_{B}$ as illustrated in Fig. 11 is determined by

$$
\phi_{B}=\phi_{\mathrm{Pt}}-\left(\chi_{\mathrm{Ge}}-C B O_{\mathrm{Al}_{2} \mathrm{O}_{3}}\right)
$$

where $\chi_{\mathrm{Ge}}$ is Ge electron affinity $(4.0 \mathrm{eV})$, and $\phi_{\mathrm{Pt}}$ is the $\mathrm{Pt}$ work function $(5.65 \mathrm{eV}){ }^{33}$ For all samples $\phi_{B}$ is determined by $\mathrm{Al}_{2} \mathrm{O}_{3} \mathrm{CBO}(3.1 \mathrm{eV})$ since this is the largest $\mathrm{CBO}$ in each sample studied. It is calculated to be $4.75 \mathrm{eV}$. For the reference sample this barrier is continuous for a distance of $4 \mathrm{~nm}$ $\left(\mathrm{Al}_{2} \mathrm{O}_{3}\right.$ thickness in the reference sample) as opposed to only $2 \mathrm{~nm}$ in the Hf-based samples. This can reduce the current contributed by electron tunneling in the reference sample. The results of the I-V measurements further establish that for all high-k studied in this work $\mathrm{HfAlO}_{\mathrm{x}}$ is the most appropriate one.

\section{CONCLUSIONS}

In this paper, we have thoroughly studied the high$\mathrm{k} / \mathrm{Al}_{2} \mathrm{O}_{3} / \mathrm{GeO}_{2} / \mathrm{Ge}$ p-MOS structure in order to find which Hf-based high-k has the most promising properties for a future high mobility channel gate stack. Electrical measurements, including $\mathrm{C}-\mathrm{V}$ in different frequencies, conductance method measurements, quasi-static $\mathrm{C}-\mathrm{V}$, hysteresis $\mathrm{C}-\mathrm{V}$ and $\mathrm{I}-\mathrm{V}$ measurements were conducted and analyzed carefully. Oxygen bonding was analyzed from the XPS O1s spectrum. The analysis reveals that the $\mathrm{O}-\mathrm{H}$ bonding exists only in $\mathrm{HfGdO}_{\mathrm{x}}$. This result is correlated with the high density of border traps measured in this sample. I-V measurements correlated to band alignment (determined by XPS) lead us to conclude that hole tunneling is the dominant current mechanism in the samples studied. We have found repeatedly that the ternary Hf-based high-k dielectrics show improvement of the electrical properties of $\mathrm{HfO}_{2}$. $\mathrm{HfAlO}_{\mathrm{x}}$ presents the best results for all systems studied in terms of electrical properties. One possible explanation to this result, which is obtained from the majority of electrical characterizations, is that the $\mathrm{Al}$ in $\mathrm{HfAlO}_{\mathrm{x}}$ improves the quality of the $\mathrm{HfMO}_{\mathrm{x}} / \mathrm{Al}_{2} \mathrm{O}_{3}$ interface. Another possible reason for the superiority of $\mathrm{HfAlO}_{\mathrm{x}}$ can be a reduction of the oxygen vacancies in $\mathrm{HfAlO}_{\mathrm{x}}$ : oxygen vacancies are known to be stable in $\mathrm{HfO}_{2}$ and much less stable in $\mathrm{Al}_{2} \mathrm{O}_{3} .{ }^{34}$ We also show that the addition of $\mathrm{Al}$ to $\mathrm{HfO}_{2}$ results in a slight decrease in relative permittivity value. This trade-off between a significant improvement of the electrical properties and a small reduction in the $k$ value is acceptable. Perhaps a smaller amount of $\mathrm{Al}$ added can maintain the electrical properties shown here with a smaller cost in reduction in $\mathrm{k}$ value.

\section{ACKNOWLEDGMENTS}

The authors acknowledge Reuven Brener for XPS measurements and Roy Winter for TEM sample preparation. This 
work was supported by the Russel Berrie Nanotechnology Institute at the Technion. Felix Palumbo is a researcher of CONICET on leave at the Technion. The research leading to these results has received funding from the European Union's_-Seventh Framework Program (FP7/2007-2013) under Grant Agreement No. 299094- MC-CONAT.

${ }^{1}$ Y. Kamata, Mater. Today 11, 30 (2008).

${ }^{2}$ C. Henkel, O. Bethge, S. Abermann, S. Puchner, H. Hutter, and E. Bertagnolli, Appl. Phys. Lett. 97, 152904 (2010).

${ }^{3}$ P. McIntyre et al., ECS Trans. 3, 519 (2006).

${ }^{4}$ P. W. Loscutoff and S. F. Bent, Ann. Rev. Phys. Chem. 57, 467 (2006).

${ }^{5}$ S. Sioncke et al., J. Appl. Phys. 110, 084907 (2011).

${ }^{6}$ A. Delabie, F. Bellenger, M. Houssa, T. Conard, S. V. Elshocht, M. Caymax, M. Heyns, and M. Meuris, Appl. Phys. Lett. 91, 082904 (2007).

${ }^{7}$ S. Takagi, R. Zhang, and M. Takenaka, Microelectron. Eng. 109, 389 (2013).

${ }^{8}$ R. Suri, C. J. Kirkpatrick, D. J. Lichtenwalner, and V. Misra, Appl. Phys. Lett. 96, 042903 (2010).

${ }^{9}$ X. F. Li, X. J. Liu, W. Q. Zhang, Y. Y. Fu, A. D. Li, H. Li, and D. Wu, Appl. Phys. Lett. 98, 162903 (2011).

${ }^{10}$ Y. Xiong, H. Tu, J. Du, M. Ji, X. Zhang, and L. Wang, Appl. Phys. Lett. 97, 012901 (2010).

${ }^{11}$ J. H. Choi, Y. Mao, and J. P. Chang, Mater. Sci. Eng. Rep. 72, 97 (2011).

${ }^{12}$ J. Robertson, J. Vac. Sci. Technol. B 18, 1785 (2000).

${ }^{13}$ O. Renault, L. Fourdrinier, E. Martinez, L. Clavelier, C. Leroyer, N. Barrett, and C. Crotti, Appl. Phys. Lett. 90, 052112 (2007).

${ }^{14}$ E. Golias, L. Tsetseris, A. Chroneos, and A. Dimoulas, Microelectron. Eng. 104, 37 (2013).

${ }^{15}$ S. Swaminathan, Y. Sun, P. Pianetta, and P. C. McIntyre, J. Appl. Phys. 110, 094105 (2011).
${ }^{16}$ J. Ahn, I. Geppert, M. Gunji, M. Holland, I. Thayne, M. Eizenberg, and P. C. McIntyre, Appl. Phys. Lett. 99, 232902 (2011).

${ }^{17}$ H. X. Xu, J. P. Xu, C. X. Li, and P. T. Lai, Appl. Phys. Lett. 97, 022903 (2010).

${ }^{18}$ S. Swaminathan, M. Shandalov, Y. Oshima, and P. C. McIntyre, Appl. Phys. Lett. 96, 082904 (2010).

${ }^{19}$ A. Delabie et al., ECS Trans. 16, 671 (2008).

${ }^{20}$ L. Nyns, D. Lin, G. Brammertz, F. Bellenger, X. Shi, S. Sioncke, S. V. Elshocht, and M. Caymax, ECS Trans. 35, 465 (2011).

${ }^{21}$ I. Krylov, L. Kornblum, A. Gavrilov, D. Ritter, and M. Eizenberg, Appl. Phys. Lett. 100, 173508 (2012).

${ }^{22}$ E. H. Nicollian and J. R. Brews, MOS (Metal Oxide Semiconductor) Physics and Technology (Wiley, New York, 1982).

${ }^{23}$ R. Engel-Herbert, Y. Hwang, and S. Stemmer, J. Appl. Phys. 108, 124101 (2010).

${ }^{24}$ K. Wandelt and C. R. Brundle, Surf. Sci. 157, 162 (1985).

${ }^{25}$ D. M. Fleetwood, IEEE Trans. Nucl. Sci. 39, 269 (1992).

${ }^{26}$ D. M. Fleetwood, M. R. Shaneyfelt, W. L. Warren, J. R. Schwank, T. L. Meisenheimer, and P. S. Winokur, Microelectron. Reliab. 35, 403 (1995).

${ }^{27}$ S. Fadida, M. Eizenberg, L. Nyns, S. Van Elshocht, and M. Caymax, Microelectron. Eng. 88, 1557 (2011).

${ }^{28}$ S. Miyazaki, Appl. Surf. Sci. 190, 66 (2002).

${ }^{29}$ I. Geppert, E. Lipp, R. Brener, S. Hung, and M. Eizenberg, J. Appl. Phys. 107, 053701 (2010).

${ }^{30}$ E. Bersch, S. Rangan, R. A. Bartynski, E. Garfunkel, and E. Vescovo, Phys. Rev. B 78, 085114 (2008).

${ }^{31}$ K. Y. Gao, T. Seyller, L. Ley, F. Ciobanu, G. Pensl, A. Tadich, J. D. Riley, and R. G. C. Leckey, Appl. Phys. Lett. 83, 1830 (2003).

${ }^{32}$ J.-P. Locquet, C. Marchiori, M. Sousa, J. Fompeyrine, and J. W. Seo, J. Appl. Phys. 100, 051610 (2006).

${ }^{33}$ H. B. Michaelson, J. Appl. Phys. 48, 4729 (1977).

${ }^{34}$ J. L. Gavartin, D. M. Ramo, A. L. Shluger, G. Bersuker, and B. H. Lee, Appl. Phys. Lett. 89, 082908 (2006). 